\title{
CAPITAL HUMANO E TECNOLOGIA: análise da produtividade agrícola da Bahia
}

\section{HUMAN CAPITAL AND TECHNOLOGY: Analysis of agricultural productivity in Bahia}

\author{
Neorley Batista Carvalho \\ Mestre, bolsista CAPES - Universidade Estadual de Santa Cruz \\ neorley@hotmail.com \\ Mônica de Moura Pires \\ Doutora - Universidade Estadual de Santa Cruz \\ mpires@uesc.br \\ Andréa da Silva Gomes \\ Doutora - Universidade Estadual de Santa Cruz \\ andreauesc@gmail.com
}

\section{Resumo}

Historicamente, as atividades agrícolas têm sido de grande relevância para a economia brasileira, impulsionando investimentos públicos e privados que modernizaram a agricultura, gerando crescimento da produção agrícola, via aumento da produtividade, e contribuindo no processo de crescimento econômico e geração de divisas para o país. No cenário agrícola nacional, o estado da Bahia tem se destacado, com seus diversos polos de produção. Diante disso, este presente trabalho analisa os ganhos de tecnologia dos cultivos mais representativos da agricultura baiana, a partir da estimação das taxas de crescimento da produtividade total de fatores (PTF), verificando a influência das variáveis capital humano e tecnologia sobre a produtividade agrícola nas microrregiões baianas. Para tanto, foi utilizada a teoria dos números-índices, a fórmula superlativa de Fisher e regressão da PTF. De acordo com os resultados, as variáveis tecnologia e capital humano influenciam fortemente na produtividade total dos fatores, e o acesso e uso dos fatores produtivos geram distintos níveis de produtividade nas microrregiões do estado da Bahia. Nesse sentido, as estratégias de ação a fim de aumentar a produtividade agrícola devem observar as particularidades locais, direcionando esforços e recursos no atendimento às demandas do meio rural de cada microrregião.

Palavras-Chave: Produtividade Total dos Fatores. Agricultura. Desenvolvimento agrícola.

\begin{abstract}
Throughout history, agricultural activities have presented high relevance to the Brazilian economy, promoting public policies and private investments that achieved modernization of agriculture, increasing the production because of yield, providing economic development of the country. In this national agricultural scenario, the state of Bahia has stood out in many and diverse poles of production generating development. For this reason, the present study aims to analyze the technological gains of the most representative products of the agriculture of Bahia state, from the estimation of growth rates of total factor productivity, verifying how the variables human capital and
\end{abstract}


technology influences and how it behaves in the micro-regions of the state. Therefore, the index number theory, Fischer's superlative formula and regression models were used to explain the influence of variables such as human capital and agricultural technology on agricultural productivity indices. According to the found results, it can be said that the variables technology and human capital have a strong influence on the total factor productivity. The differences in access and use of these factors provide different levels of growth among the micro-regions of the state of Bahia. In this sense, specific intervention strategies are needed for some localities in rural Bahia, applying efforts and funds in order to achieve the requirements of each micro-region.

Keywords: Total Productivity of Factors. Agriculture. Agricultural development.

\section{Introdução}

A crescente adoção de sofisticadas tecnologias, em diversas atividades humanas, demonstra ser algo contínuo. Na agricultura, a absorção das inovações tecnológicas provoca grandes mudanças que alteraram a relação entre os fatores de produção e o produto final obtido no processo produtivo.

Historicamente, as atividades agrícolas no Brasil têm sido de grande relevância para a economia, citam-se a cana de açúcar, o café e o cacau, que exerceram grande relevância na geração de divisas para o país. A partir da década de 1960, a agricultura brasileira passou por grande transformação, decorrente do processo de modernização, baseado no pacote tecnológico da revolução verde, que se consolidou na década de 1970 com formação dos complexos agroindustriais (ROCHA et al. 2002).

Os resultados desses investimentos na agricultura podem ser retratados pelos saldos positivos para a economia do país, e por se situar entre os melhores desempenhos dentre os setores produtivos brasileiro. De acordo com o Ministério da Agricultura, o PIB do agronegócio em 2014 representou quase 23\% do PIB total da economia brasileira, cerca de R\$1,1 trilhão. Desse percentual, as atividades agrícolas significaram $70 \%$ e a pecuária cerca de $30 \%$ do valor produzido naquele ano. Em 2015, dados do Instituto Brasileiro de Geografia e Estatística (IBGE), mostraram ainda, que mesmo com a retração do PIB brasileiro, o setor agropecuário expandiu 1,8\% em comparação ao ano anterior, principalmente pelos resultados positivos da soja e do milho, que cresceram $11,9 \%$ e $7,3 \%$, respectivamente, em 2015 . 
Nesse cenário agrícola nacional, a Bahia se destaca com seus diversos polos produtivos, e a partir dos anos 1980 os investimentos em modernização da agricultura baiana, pode ser notada pelo aumento da frota de tratores, pelo uso de fertilizantes e pelas áreas irrigadas. Conforme dados do IBGE, no ano de 2010 o setor agropecuário representava 7\% do PIB do estado da Bahia, um crescimento de 6\% em relação a 2009 e um recorde de produção com 6,7 milhões de toneladas, conforme os dados da Pesquisa Agrícola Municipal (PAM, 2010). Esse crescimento decorreu do bom desempenho das safras da Bahia, destacando-se as lavouras de cacau, que expandiram 8,2\%, cana-deaçúcar (7,5\%) e café (4,8\%). Observaram-se, também, incrementos positivos na produção de soja (28,3\%), algodão (8,7\%) e milho (3,0\%). Em 2016, dados do IBGE/PAM (2016), revelam que diferentemente dos outros setores da economia baiana, a agricultura cresceu, especialmente pela safra de grãos no estado que apresentou crescimento de $3,1 \% \mathrm{em}$ janeiro de 2016 (9,6 milhões de toneladas) em relação a janeiro de 2015, apesar da redução na área plantada de 7,6\%, destacando as lavouras de soja e milho. Esses números projetam a Bahia no cenário agrícola brasileiro, porém esses valores positivos ocorrem de forma distinta no território. Daí a importância de identificar e analisar a produtividade agrícola nas diferentes microrregiões do estado.

Estudo realizado por Vicente et al. (2003), utilizando a Produtividade Total dos Fatores (PTF), para os estados brasileiros, apontou que em 1995, os estados de São Paulo, Espírito Santo, Goiás, Mato Grosso do Sul, Mato Grosso e Minas Gerais se destacavam no contexto agrícola nacional. Por outro lado, Piauí, Maranhão e Ceará se encontravam em situação oposta, devido à falta de incentivo ao setor, como o crédito rural. De maneira semelhante, o estado da Bahia apresentava fraco crescimento da agricultura em relação à média brasileira, embora ocupasse o quinto melhor desempenho entre os estados da região Nordeste. Os autores evidenciaram, ainda, que as regiões Norte e Nordeste do país possuíam os piores desempenhos agrícolas quando comparados às regiões Sul, Sudeste e Centro Oeste, resultantes das diferenças no processo de modernização da agricultura.

Partindo-se desses estudos, busca-se identificar quais foram as mudanças ocorridas no padrão de produtividade agrícola nas microrregiões da Bahia e como os fatores de produção - tecnologia, trabalho, capital - afetam a produtividade. A pergunta que se faz é se ocorreria internamente na Bahia o mesmo cenário observado por Vicente et al. (2003) 
para os estados brasileiros ou se esse processo seria distinto. Para responder a essas questões supõe-se que a tecnologia e o capital humano são variáveis chaves na explicação das diferenças de produtividade agrícola na Bahia. Espera-se com esta análise, subsidiar na elaboração de políticas agrícolas que possam gerar maior desenvolvimento ao meio rural.

\section{Referencial teórico}

$\mathrm{Na}$ literatura econômica, os fatores de produção são comumente relacionados à terra (uso da terra), ao capital físico (equipamentos, máquinas, etc.), ao capital humano (capacidade produtiva dos indivíduos) e à tecnologia (relacionado à capacidade de inovar). Esses fatores estão presentes em diversos estudos que estimam funções de produção $^{1}$ relacionadas ao crescimento econômico. Citam-se, como exemplos, os modelos neoclássicos de crescimento econômico como o de Solow (1956), Harrod (1939) e Domar (1946), nos quais os fatores de produção são determinantes para o crescimento de uma determinada região. De acordo com Thirwall (2005), o modelo neoclássico de crescimento baseia-se em três pressupostos:

\footnotetext{
O primeiro é que força de trabalho e o progresso tecnológico economizador de mão de obra crescem a uma taxa exógena constante. O segundo é que toda a poupança é investida, não havendo função de investimento independente. $O$ terceiro pressuposto é que a produção é função do capital e do trabalho e nele exibe rendimento constantes de escala e rendimentos decrescentes dos fatores de produção. (THIRWALL, 2005, p. 29).
}

A partir da década de 1980 avançaram os modelos de crescimento endógenos, como os modelos AK e o de Lucas (1988). Esses modelos consideravam que a inovação derivava de uma decisão ótima, a partir da aprendizagem pela experiência. Assim, o crescimento econômico de um país, segundo tais modelos, dependeria da quantidade de insumos empregados em P\&D.

Assim, o crescimento é endógeno, e conforme Romer (1986) e Lucas (1988), essa endogeneização do processo tecnológico deriva da troca de experiências pela inovação e transferência de conhecimento. Portanto, a cooperação mútua geraria externalidades positivas em função dos spillovers de conhecimento, ou seja, a disseminação tecnológica contribuiria para o crescimento econômico. 
Além disso, muitos trabalhos passaram a incorporar o progresso técnico a partir do capital humano, referenciando a importância desse fator de produção no crescimento de uma região. Esse conceito de capital humano tornou-se mais evidente a partir das obras seminais de Mincer (1958), Schultz (1964) e Becker (1964). Em Mincer (1958) a abordagem econométrica adotada detectou uma relação positiva entre produtividade e rendimentos dos indivíduos, resultado de investimentos em capital humano. Para Schultz (1964) e Becker (1993), os investimentos em educação são imprescindíveis para o crescimento econômico já que permitiriam realçar as dotações individuais.

Dessa forma, o investimento em capital humano é fundamental, pois atua de forma incontestável no crescimento da produção, sendo responsável, em grande parte, pelo crescimento dos rendimentos reais por trabalhador (SCHULTZ, 1973). Em Becker (1993) a ênfase é dada pela abordagem custo-benefício, ou seja, quanto mais investimento na formação do indivíduo, maior deverá ser a sua remuneração.

Embora esses estudos ressaltem a importância do capital humano no crescimento econômico, o grande desafio está na sua mensurabilidade, ao considerar a intangibilidade desse fator de produção. De fato, como mensurar a habilidade ou talento de um determinado indivíduo, incorporando essa variável em uma função de produção?

Nesse esforço de estimação, a literatura sobre o tema vem utilizando alguns indicadores para revelar a importância do capital humano na produção. Dentre os mais empregados estão: média de escolaridade por região e faixa etária, percentual da população por nível de educação (primário, secundário, médio ou superior) e número de pessoas matriculadas por nível educacional (VIANA e LIMA, 2010), além de anos médios de escolaridade da população (GOMES et al., 2003).

Ademais, os estudos sobre capital humano realçam também a sua influência sobre a produtividade total dos fatores (PTF) dos setores produtivos sobre o crescimento econômico de uma região. Assim, ao medir a PTF é possível estimar a eficiência do uso dos fatores produtivos, por ser uma análise que inclui multifatores, indo além da mão de obra, pois incorpora também as matérias-primas e os serviços de capital empregados na produção. Daí seu uso como medida de análise do progresso tecnológico.

A influência do capital humano na determinação da PTF está presente nos estudos de Gomes et al. (2003) que analisaram a evolução da PTF para a economia brasileira de 
1950 a 2000, e em Barbosa Filho et al. (2010) que apresentam uma abordagem comparativa entre países por meio da produtividade marginal do trabalho. Já em Ferraz (2016) a PTF é analisada em uma perspectiva agrícola, o qual aponta a relevância do uso de tecnologias na agricultura como informação, automação, robótica, engenharia genética, química, processos, materiais, gestão integrada, entre outras, no aumento da produção via produtividade dos fatores. Daí surgem os conceitos de smart farm ou smart agriculture e agricultura de precisão, em que o uso de informação, automação e robótica, torna possível acompanhar amiúde o desenvolvimento dos plantios no campo.

Para Hayami e Ruttan (1988), as novas tecnologias aplicadas à agricultura decorrem também da substituição dos fatores mais escassos pelos menos escassos. Assim, a tecnologia mecânica é "poupadora de mão de obra" e a tecnologia biológica ou química é "poupadora de terra". Desse modo, a tecnificação da produção agrícola permitiria "poupar" insumos e aumentar a produtividade total dos fatores.

Elias (2005) acrescenta ainda que o amplo emprego de máquinas, insumos químicos e biotecnológicos fornecidos pelo setor industrial, geraram transformações relevantes nas relações sociais de produção, e consequentemente na divisão social e territorial do trabalho agropecuário.

Entende-se, portanto, que o capital humano está intrinsecamente associado às inovações tecnológicas, haja vista que regiões ou produtores com maior nível de conhecimento poderão absorver e utilizar as novas tecnologias com maior eficiência. Essas são relações complexas e importantes de serem analisadas, pois ao se compreender a magnitude da contribuição do capital humano e da tecnologia na composição da produtividade total dos fatores é possível identificar elementos condutores de ações e medidas mais eficientes, setorialmente, pelos tomadores de decisão. E, neste estudo, em especial para o setor agrícola baiano, haja vista que as análises em nível de microrregião, ainda não foram realizadas para o estado da Bahia.

\section{Metodologia}

O estado da Bahia possui quase 30 milhões de hectares de área rural ocupados por 761.558 estabelecimentos agropecuários, conforme o Censo Agropecuário de 2006 do Instituto Brasileiro de Geografia e Estatística (IBGE). Em termos populacionais, o Censo 
Demográfico de 2010 do IBGE, aponta uma população rural de 3.914.430, cerca de 28\% da população total do estado da Bahia, distribuída em 417 municípios e 32 microrregiões geográficas.

Os dados utilizados neste trabalho foram obtidos do Censo Agropecuário do IBGE para os anos de 1975, 1980, 1985, 1995 e 2006, do Instituto de Economia Agrícola de São Paulo (IEA), do Ministério da Agricultura, Pecuária e Abastecimento do Brasil (MAPA) e da Fundação Getúlio Vargas (FGV). O Quadro 1 apresenta as variáveis utilizadas e as respectivas fontes dos fatores de produção utilizados no cálculo dos índices de produtividade.

Quadro 1: Variáveis utilizadas no cálculo dos índices de produtividade

\begin{tabular}{|c|c|c|}
\hline Fator de produção & Variável $^{1}$ & Fonte \\
\hline \multirow{2}{*}{ Terra } & Área colhida & $\begin{array}{l}\text { IBGE - PAM, Disponível em: } \\
\text { http://www.ipeadata.gov.br/ } \\
\text { Acesso em: } 14 \text { out. } 2016\end{array}$ \\
\hline & Arrendamento da terra & $\begin{array}{l}\text { FGV, Disponível em: } \\
\text { http://portalibre.fgv.br/ Acesso } \\
\text { em: } 14 \text { out. } 2016\end{array}$ \\
\hline \multirow{2}{*}{ Mão de obra } & $\mathrm{N}^{\mathrm{o}}$ pessoal ocupado & $\begin{array}{l}\text { Censo Agropecuário, Disponível } \\
\text { em: http://www.ipeadata.gov.br/ } \\
\text { Acesso em: } 14 \text { out. } 2016\end{array}$ \\
\hline & $\begin{array}{l}\text { Gastos com salários / } \mathrm{N}^{\circ} \\
\text { pessoal ocupado }\end{array}$ & $\begin{array}{l}\text { Censo Agropecuário, Disponível } \\
\text { em: http://www.ipeadata.gov.br/ } \\
\text { Acesso em: } 14 \text { out. } 2016\end{array}$ \\
\hline \multirow[b]{2}{*}{ [Máquinas } & $\begin{array}{c}\mathrm{N}^{\circ} \text { máquinas e } \\
\text { equipamentos agrícolas }\end{array}$ & $\begin{array}{l}\text { Censo agropecuário }(1975,1980, \\
1985)^{2} \text { e }(1995,2006)^{3}\end{array}$ \\
\hline & $\begin{array}{c}\text { Valor das máquinas e } \\
\text { equipamentos / } \mathrm{N}^{\circ} \\
\text { máquinas e equipamentos }\end{array}$ & $\begin{array}{l}\text { Censo agropecuário }(1975,1980 \text {, } \\
1985)^{2} \text { e }(1995,2006)^{3}\end{array}$ \\
\hline \multirow{2}{*}{ Fertilizantes } & Quantidade em tonelada & $\begin{array}{l}\text { Censo agropecuário }(1975,1980 \text {, } \\
1985)^{2} \mathrm{e}(1995,2006)^{3}\end{array}$ \\
\hline & Preços & Dados fornecidos pelo MAPA \\
\hline \multirow[t]{2}{*}{ LDefensivos } & Quantidade em tonelada & $\begin{array}{l}\text { Despesas: Censo agropecuário } \\
(1975,1980,1985)^{2} \text { e }(1995 \text {, } \\
2006)^{3}\end{array}$ \\
\hline & Preços & Dados fornecidos pelo MAPA ${ }^{4}$ \\
\hline
\end{tabular}

Notas: ${ }^{1}$ Todos os valores deflacionados para dez. 2006. ${ }^{2}$ Publicações impressas. Disponível em:

$<$ http://biblioteca.ibge.gov.br/index.php/biblioteca-catalogo?view=detalhes\&id=745>. Acesso em: 15 out. 2016. ${ }^{3}$ Banco de dados SIDRA. Disponível em:

$<\mathrm{http}: / /$ www.sidra.ibge.gov.br/bda/acervo/acervo9.asp?e=c\&p=CA\&z=t\&o=3>. Acesso em: 15 out. 2016. 
${ }^{4}$ Informações cedidas via e-mail pelo Coordenador de Planejamento Estratégico do Ministério da Agricultura Pecuária e Abastecimento.

Fonte: Elaborado pelos autores.

A quantidade de fertilizantes e defensivos foi obtida pela razão entre despesa total no ano e preço médio no ano. Nos censos agropecuários de 1985 e 1995, as despesas não foram informadas por tipo de insumo para as microrregiões, assim estimou-se o percentual empregado de fertilizantes e defensivos a partir do total das despesas do estado da Bahia, e em seguida esse percentual foi multiplicado pela despesa total por microrregião geográfica. Os preços dos fertilizantes e dos defensivos agrícolas foram estimados a partir de valores médios nacional disponibilizados pelo MAPA.

Para a construção do índice de produção foram utilizadas 18 culturas: algodão herbáceo, amendoim, arroz, batata inglesa, banana, cacau, café, feijão, fumo laranja, mandioca, milho e pimenta do reino. Essa escolha baseou-se na importância dessas culturas, as quais agregadamente representam mais de $85 \%$ da quantidade produzida no estado da Bahia, conforme IBGE/PAM (2006).

Após as adequações dos dados, estimou-se a produtividade, dada pela razão entre o índice de produção e o índice o índice de insumo. A fórmula utilizada foi a de Fisher, tomando como referência Vicente (2012), expressa por:

$$
F Q_{0,1}=\sqrt{\frac{\sum_{i=1}^{n} p_{0}^{i} q_{1}^{i}}{\sum_{i=1}^{n} p_{0}^{i} q_{0}^{i}} \cdot \frac{\sum_{i=1}^{n} p_{1}^{i} q_{1}^{i}}{\sum_{i=1}^{n} p_{1}^{i} q_{0}^{i}}}
$$

em que FQ identifica o índice Fisher de quantidade na microrregião em questão, $p_{1}^{i}$ é o preço do $i$-ésimo produto (ou insumo) no ano t, $p_{0}^{i}$ o preço do $i$-ésimo produto (ou insumo) no ano $\mathrm{t}-1, q_{1}^{i}$ a quantidade do $i$-ésimo produto (ou insumo) no ano $t$ e $q_{0}^{i}$, a quantidade do $i$-ésimo produto (ou insumo) no ano t-1.

Como foram utilizados distintos e longos períodos de análise, a literatura sugere adotar um processo de encandeamento, com a atualização da base de cálculo, a fim de reduzir os desvios significativos quando se aplica uma base fixa. O uso desse procedimento permite, assim, captar alterações substanciais que podem ter ocorrido na produção, em decorrência de fatores econômicos e ambientais. Esse cálculo de encadeamento foi feito por meio do uso da fórmula de Fisher:

$$
\begin{aligned}
& \mathrm{FQ}^{e}{ }_{\mathrm{t}}=\mathrm{FQ}_{\mathrm{t}} \mathrm{FQ} \mathrm{FQ}_{\mathrm{t}-1} \\
& \mathrm{FQ}_{\mathrm{t}+1}=\mathrm{FQ}_{\mathrm{t}+1} \mathrm{xFQ}_{\mathrm{t}} \\
& \mathrm{FQ}^{e}{ }_{t+n}=\mathrm{FQ}_{\mathrm{t}+\mathrm{n}} \mathrm{XQ}^{e} \mathrm{t}-\mathrm{n}
\end{aligned}
$$


em que os valores sem o subscrito $e$ referem-se aos índices antes do encadeamento; os valores com subscrito $e$ são os índices já encadeados.

Após estimar os índices de produção, insumo e PTF, buscou-se explicar o que poderia determinar essa produtividade aplicando um painel de dados para as PTF estimadas. Esse painel é uma combinação de cortes seccionais com série temporal. O método aplicado foi o caso particular do modelo de regressão múltipla, conhecido como estimador de variáveis dummies ou binárias, ou ainda, de efeitos fixos (GREENE, 1995; JUDGE et al., 1988). Formalmente, $i=1,2, \ldots, N$ as observações dos cortes seccionais das microrregiões, e de $t=1,2, \ldots, T$ as das séries temporais (anos), o modelo de variáveis binárias (efeitos fixos) pode ser descrito como:

$$
\gamma_{i t}=\alpha_{i}+\beta x_{i t}+\varepsilon_{i t}
$$

em que $\alpha_{i}$ representa o coeficiente do intercepto para a $i$-ésima unidade de corte seccional, $\beta$ representa os coeficientes angulares que são comuns a todas as unidades, os $x_{i t}$ são as variáveis explicativas, e $\varepsilon_{i t}$ são erros aleatórios e independentes.

Adotou-se efeito fixo porque parte-se do princípio que as microrregiões baianas possuem distintas características, as quais podem influenciar as variáveis explicativas. Dessa forma, o modelo de efeito fixo permite controlar esses diferentes fatores, os quais poderiam viesar ou prejudicar o poder explicativo das variáveis selecionadas. O modelo de efeitos fixos foi estimado usando mínimos quadrados ordinários. As estimativas obtidas foram não tendenciosas e consistentes, uma vez que o modelo pressupõe que os erros possuem distribuição normal, variância constante e não são correlacionados.

No presente trabalho adotou-se o modelo representado na equação (4), em que o as PTF referem-se ao $\gamma_{i t}$ da equação (3), $i$ representa cada uma das 32 microrregiões do estado da Bahia e $t$ os anos de 1985, 1995 e 2006, $x_{i t}$ são as variáveis utilizadas para explicar a PTF (escolaridade, investimento e assistência técnica). A função estimada foi obtida da seguinte forma:

$$
\mathrm{PTF}=\alpha_{i}+\beta_{1} \text { Escolaridade }+\beta_{2} \text { Investimento }+\beta_{3} \text { Assistência técnica }+\varepsilon_{i t}
$$

O capital humano foi denominado na equação (4) de escolaridade, sendo estimado pela taxa de pessoas com 18 anos ou mais que concluíram o ensino médio nos anos de 
1991, 2000 e 2010. Os dados tiveram como fonte o Atlas do Desenvolvimento Humano do Brasil e foram coletados para os municípios do estado da Bahia e realizado uma média para cada microrregião geográfica. Esses são anos distintos das análises, o que em certa medida constitui-se em uma limitação do estudo. Além da escolaridade outra variável proxy para captar a influência do capital humano foi a assistência técnica. Nesse caso os dados utilizados foram o número de estabelecimentos que receberam assistência técnica, obtidos dos dados dos Censos Agropecuários. Para obter a proporção de assistência técnica por microrregião, dividiu-se o número total de estabelecimento de cada microrregião pelo número de estabelecimentos que declararam ter recebido assistência técnica. Espera-se que essa variável apresente sinal negativo pois quanto menor o resultado desta razão, maior número de estabelecimentos que receberam assistência técnica, proporcionalmente na microrregião analisada.

Para analisar a tecnologia foi utilizada a intensidade de mecanização das lavouras por microrregião da Bahia. Esse dado foi estimado pela razão entre área colhida total e quantidade de tratores em cada microrregião. Assume-se que a mecanização influencia positivamente a produtividade total de fatores, portanto, espera-se que a razão área/tratores seja negativo, pois quanto maior a área trabalhada por um trator menor a intensidade de mecanização, logo, menor produtividade.

Para a irrigação e uso de fertilizantes foi utilizado o mesmo procedimento da mecanização, nesse caso a intensidade de áreas irrigadas e a utilização de fertilizantes em relação ao total de área colhida. Quanto maior a área irrigada por hectare e por tonelada de fertilizante utilizado, menor a intensidade de irrigação e menor o uso de fertilizante, consequentemente se espera uma relação negativa desses fatores com a produtividade.

Espera-se que a variável investimento apresente relação positiva com o nível de modernização da agricultura e, consequentemente, com a produtividade. Essa foi considerada uma variável proxy para a tecnologia, pois assume-se aqui que a aquisição de máquinas, tratores, irrigação entre outras ações estão diretamente relacionadas à modernização do setor agropecuário. Esses dados foram coletados no site IPEADATA.

O modelo de regressão foi o log-log, sendo estimado no software Eviews v7. 


\section{Resultados e discussão}

De acordo com a Figura 1, nota-se uma restruturação produtiva na agricultura do estado da Bahia, comparando-se os principais cultivos e sua espacialização nos anos de 1975 e 2006. Essas mudanças decorreram da inserção de novos cultivos, irrigação e mecanização, em especial soja e algodão no oeste baiano.

Esse aumento tecnológico nos cultivos da soja, do algodão, do milho e da cana de açúcar levou a Bahia a ocupar lugar de destaque no cenário nacional, pelo aumento da produção e pela geração de divisas para a economia local. Em termos da produção agrícola, esses quatro cultivos passaram a representar, conjuntamente 35\% (1995), 46\% (2006), chegando a 59\% em 2014 da produção total da Bahia. Em valor de produção representaram em 2014, quase 50\% do total do valor da produção agrícola da Bahia.

Figura 1: Mapa dos principais cultivos agrícolas (em valor de produção), Bahia

1975

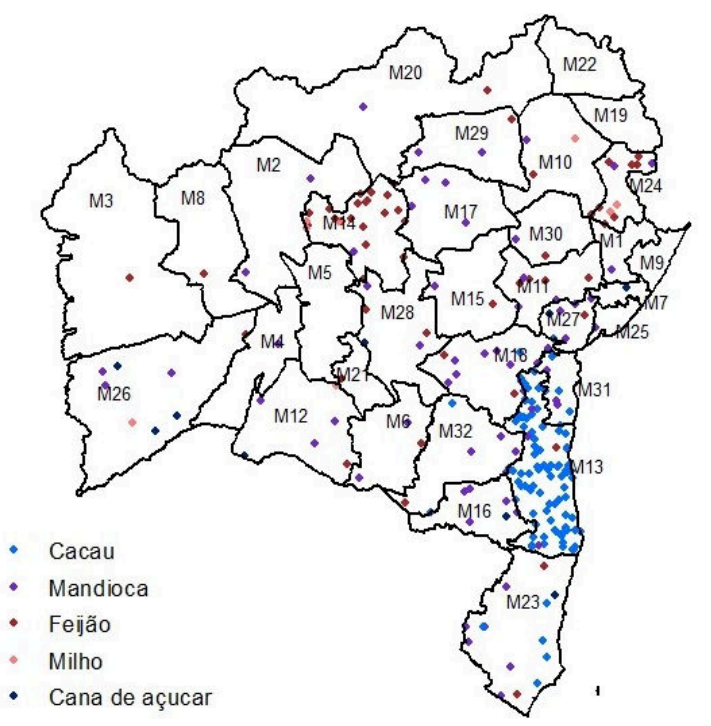

2006

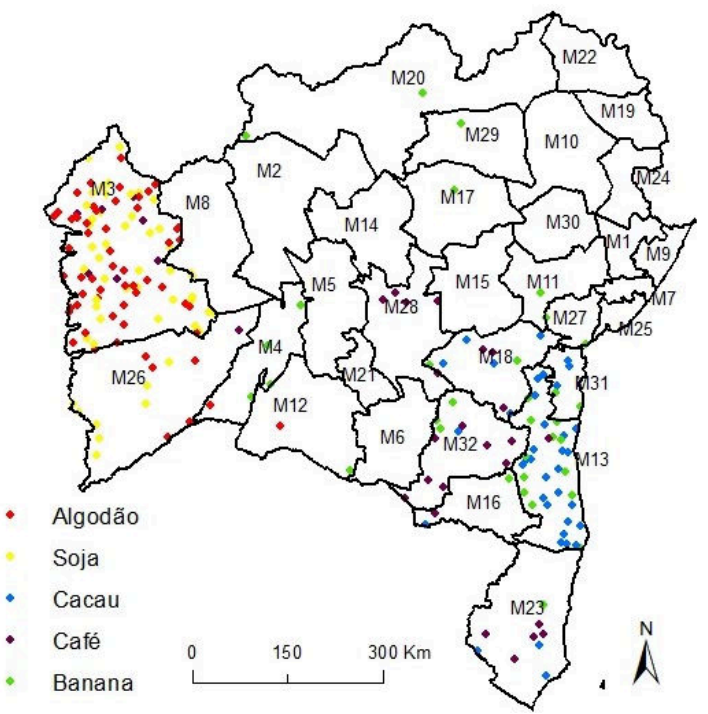

Nota: $\mathrm{M} 1=$ =Alagoinhas; $\mathrm{M} 2=$ =Barra; $\mathrm{M} 3=$ =Barreiras; $\mathrm{M} 4=$ =Bom Jesus da Lapa; M5=Boquira; M6=Brumado; M7=Catu; M8=Cotegipe; M9=Entre Rios; M10=Euclides da Cunha; M11=Feira de Santana; M12=Guanambi; M13= Ilhéus - Itabuna; M14=Irecê; M15=Itaberaba; M16=Itapetinga; M17=Jacobina; M18=Jequié; M19= Jeremoabo; M20= Juazeiro; M21=Livramento do Brumado; M22=Paulo Afonso; M23=Porto Seguro; M24=Ribeira do Pombal; M25=Salvador; M26=Santa Maria da Vitória; M27=Santo Antônio de Jesus; M28=Seabra; M29=Senhor do Bonfim; M30=Serrinha; M31=Valença; M32=Vitória da Conquista.

Fonte: Elaborada pelos autores a partir de dados do IBGE - PAM 1975 e 2006. 
Por outro lado, os cultivos tradicionais, pouco avançaram em mecanização, apresentando retração na produção. Em relação à queda na produção de cacau em quase 45\% entre 1975 e 2006, deveu-se a fatores endógenos (infestação dos cacauais da doença vassoura de bruxa ao final dos anos 1980) e exógenos (queda do preço e maior concorrência no mercado internacional), os quais desestimularam investimentos para o controle da doença, haja vista que não eram compensados pelo preço. Outras culturas tradicionais como mandioca, cebola, tomate, amendoim, feijão, arroz, pimenta do reino dentre outras, poucas foram as transformações observadas em termos de mecanização, sendo caracteristicamente de pequena e média escala, intensivos no uso de mão de obra e para abastecimento do mercado local ou regional.

De acordo com os Censos Agropecuários do IBGE, em 1975 o cacau representava o principal produto do estado da Bahia em termos de valor de produção, seguido de mandioca, feijão, milho e cana de açúcar. Em 2006, há uma mudança substancial nesse posicionamento, passando então a ocupar lugar de destaque a soja e o algodão, que em 1975 ocupavam a posição 11 e 17, respectivamente, em termos de produção.

Nessas mudanças, nota-se que as culturas mais relevantes para a agricultura da Bahia são temporárias, o que representa uma nova forma organizativa do setor agropecuário, conforme observado também por Couto Filho (2004b). Segundo esse autor, isso ocorreu pela inserção de commodities em um modelo produtivista, com uso de grandes áreas, irrigação, e busca por maiores rendimentos físicos e retorno mais rápido do capital investido.

Analisando o índice de produtividade total dos fatores (PTF), Gráfico 1, verificase que em um período de três décadas (1975-2006), a trajetória é de baixo crescimento, pois o acréscimo foi de apenas 13\% nesse período (a PTF passou de 100 em 1975 para 113 em 2006). Desagregando a PTF em índice de insumo e índice de produção, nota-se que o primeiro supera o segundo, indicando menor aumento da produção comparativamente ao uso de insumos. Entre 1995 e 2006 o índice de produção ultrapassa o índice de insumos, revelando crescimento da produtividade. Esse mesmo fenômeno foi observado por Gasques e Conceição (2000) em uma análise para o Brasil, sendo que para a Bahia, os índices de insumos foram mais elevados comparativamente aos de produção, 
e mesmo à PTF. Isso mostra que os dados de 2006 apresentam transformações relevantes na agricultura baiana.

Gráfico 1: Evolução dos índices de produtividade total, índice do produto e índice de insumos Bahia, Bahia, 1975 a 2006

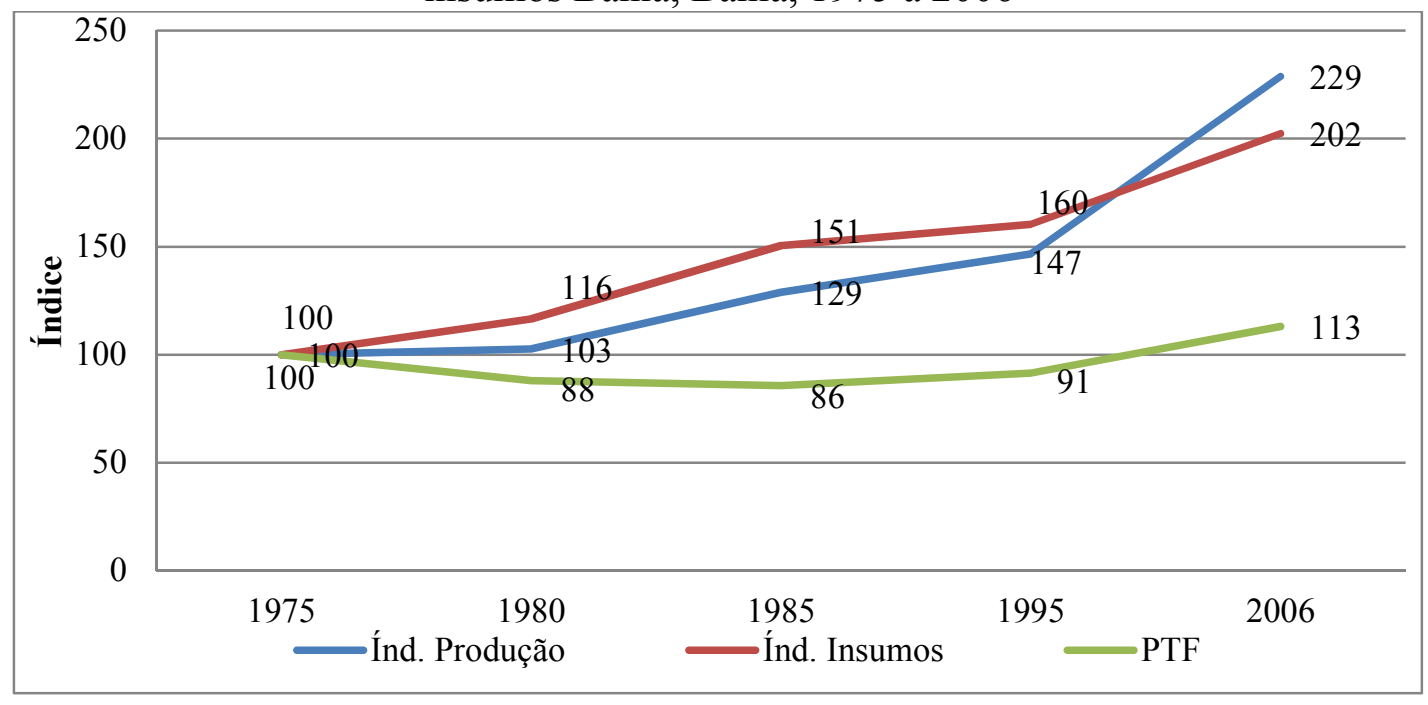

Fonte: Elaborada pelos autores.

Maior eficiência no uso dos insumos faz com que a curva de PTF seja cada vez mais ascendente, pois com uma menor quantidade de insumos consegue-se obter maior nível de produção, resultado dos ganhos de produtividade. Em geral, os fatores que podem contribuir com esse fenômeno, relacionam-se à incorporação da tecnologia e aos ganhos externos de escala decorrentes da economia de aglomeração. Essas vantagens, podem ser notadas pela concentração de plantios em uma região e pela de economia de escala, a exemplo da produção de soja, milho e algodão no oeste baiano.

Viana (2004), Couto Filho (2004a), Guilhoto (2007), Bispo (2012) dentre outros, apontam que o crescimento do setor agropecuário da Bahia pode ser medido pela participação do setor no PIB total e pelo Valor Bruto da Produção (VBP). Contudo, relatam que esse crescimento ocorre de forma desigual dentro do estado. Um exemplo disso é a região oeste baiana que passou a ter um peso preponderante na renda gerada pelo setor agropecuário do estado, na qual estão os principais municípios produtores de commodities e uma agricultura empresarial e moderna.

Em relação aos índices parciais de produtividade, houve crescimento da produtividade da terra e da PTF, porém com poucos ganhos. Em contrapartida, a 
produtividade da mão de obra cresceu consideravelmente após 1985, enquanto diminuiu a produtividade das máquinas e equipamentos agrícolas. Conforme dados dos Censos Agropecuários do IBGE, a área colhida no estado passou de pouco mais de 2 milhões de hectares em 1975 para quase 4 milhões de hectares em 2006, um aumento de quase 80\%, resultando em um crescimento moderado do índice de produtividade da terra. Porém, à medida que o fator terra seja mais escasso, espera-se uma maior taxa de crescimento do índice de produtividade da terra.

Quanto à produtividade da mão de obra, essa se manteve praticamente inalterada durante os anos de 1980 a 1985 e, posteriormente, apresentou crescimento expressivo. Um dos fatores para esse comportamento, foi o maior uso de tecnologias intensivas em capital, as quais são poupadoras de mão de obra. O número de máquinas e equipamentos no período de 1975 a 2006, cresceu acima de 190\%, enquanto o número de pessoas ocupadas diminuiu 7,64\%. O crescimento das culturas temporárias mais intensivas em capital, como soja, milho e algodão, fez com que o número de trabalhadores por hectare diminuísse. Tal resultado se assemelha ao obtido por Couto Filho (1999), que aponta redução do percentual de mão de obra ocupada em atividades agropecuárias nas regiões modernas, e aumento nas regiões tradicionais.

O baixo índice de produtividade parcial das máquinas e dos equipamentos agrícolas na Bahia, pode ser atribuído ao pouco uso de tecnologias mais modernas. Os dados do Censo Agropecuário revelam elevado número de equipamentos como arados de tração animal, e em menor quantidade equipamentos mecânicos como tratores. As microrregiões Barreiras, Juazeiro e naquelas onde a agricultura é considerada moderna, o nível de produtividade parcial do capital é positivo, porém, agregadamente a produtividade desse fator pode ser considerada baixa. De acordo com Pivoto (2016), como a produção de grãos e cana-de-açúcar se concentra, em grande parte, na região oeste da Bahia, têm-se nessas microrregiões os melhores resultados dos índices parciais do capital, comparativamente àquelas menos intensivas em tecnologias mais modernas.

$\mathrm{Na}$ Tabela 1 estão expostos os índices de PTF por microrregião da Bahia, em que se notam distintos níveis de crescimento de produtividade para os anos analisados. Tal fato está relacionado às diferentes características históricas, geográficas, agrícolas e também das políticas adotadas ao longo do tempo. 
Tabela 1: Índice de produtividade total dos fatores por microrregião da Bahia, 1975 a 2006

\begin{tabular}{|c|c|c|c|c|c|}
\hline \multirow{2}{*}{ Microrregião } & \multicolumn{5}{|c|}{ PTF } \\
\hline & 1975 & 1980 & 1985 & 1995 & 2006 \\
\hline Juazeiro & 100 & 112 & 303 & 584 & 646 \\
\hline Alagoinhas & 100 & 139 & 116 & 606 & 637 \\
\hline Euclides da Cunha & 100 & 31 & 133 & 90 & 270 \\
\hline Entre Rios & 100 & 130 & 86 & 147 & 203 \\
\hline Jeremoabo & 100 & 74 & 119 & 115 & 186 \\
\hline Seabra & 100 & 64 & 102 & 66 & 186 \\
\hline Bom Jesus da Lapa & 100 & 134 & 81 & 84 & 164 \\
\hline Barreiras & 100 & 59 & 68 & 166 & 160 \\
\hline Santo Antônio de Jesus & 100 & 115 & 119 & 122 & 152 \\
\hline Ribeira do Pombal & 100 & 71 & 63 & 101 & 151 \\
\hline Paulo Afonso & 100 & 98 & 127 & 299 & 141 \\
\hline Serrinha & 100 & 84 & 128 & 46 & 128 \\
\hline Porto Seguro & 100 & 102 & 71 & 91 & 115 \\
\hline Vitória da Conquista & 100 & 128 & 151 & 143 & 110 \\
\hline Boquira & 100 & 58 & 85 & 47 & 98 \\
\hline Barra & 100 & 109 & 62 & 30 & 94 \\
\hline Senhor do Bonfim & 100 & 84 & 102 & 71 & 86 \\
\hline Jacobina & 100 & 82 & 96 & 30 & 80 \\
\hline Feira de Santana & 100 & 60 & 73 & 47 & 79 \\
\hline Itaberaba & 100 & 114 & 103 & 115 & 75 \\
\hline Jequié & 100 & 88 & 100 & 57 & 74 \\
\hline Valença & 100 & 83 & 67 & 43 & 74 \\
\hline Catu & 100 & 104 & 112 & 105 & 73 \\
\hline Ilhéus-Itabuna & 100 & 87 & 89 & 68 & 61 \\
\hline Guanambi & 100 & 84 & 108 & 45 & 59 \\
\hline Itapetinga & 100 & 80 & 57 & 65 & 50 \\
\hline Livramento do Brumado & 100 & 43 & 51 & 36 & 49 \\
\hline Cotegipe & 100 & 79 & 58 & 51 & 45 \\
\hline Irecê & 100 & 87 & 53 & 13 & 43 \\
\hline Santa Maria da Vitória & 100 & 30 & 36 & 61 & 39 \\
\hline Brumado & 100 & 57 & 86 & 25 & 35 \\
\hline Salvador & 100 & 129 & 75 & 134 & 31 \\
\hline Bahia & 100 & 88 & 86 & 91 & 113 \\
\hline
\end{tabular}

Fonte: Elaborada pelos autores.

Espacializando-se os dados da Tabela 1 (Figura 2), constata-se que os maiores índices de PTF, em geral, estão concentrados nas microrregiões com culturas destinadas à agroindústria e exportação. Destacam-se as microrregiões de Alagoinhas e Juazeiro com 
os plantios de cana de açúcar, milho, soja e laranja, que apresentaram elevados índices de PTF.

Figura 2: Índice da produtividade total dos fatores por microrregião da Bahia
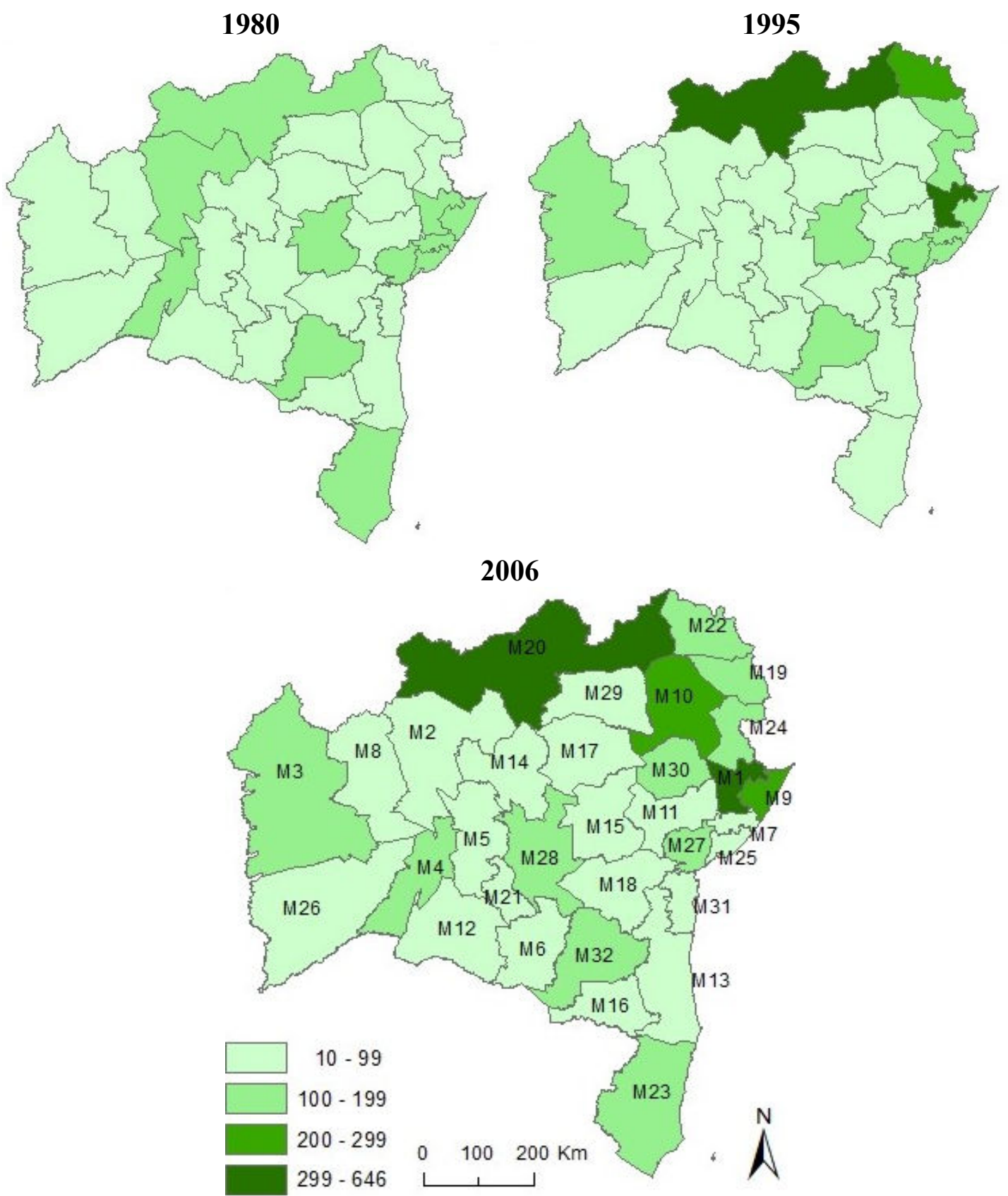

Nota: M1=Alagoinhas; M2=Barra; M3=Barreiras; M4=Bom Jesus da Lapa; M5=Boquira; M6=Brumado; M7=Catu; M8=Cotegipe; M9=Entre Rios; M10=Euclides da Cunha; M11=Feira de Santana; M12=Guanambi; M13= Ilhéus - Itabuna; M14=Irecê; M15=Itaberaba; M16=Itapetinga; M17=Jacobina; M18=Jequié; M19= Jeremoabo; M20= Juazeiro; M21=Livramento do Brumado; M22=Paulo Afonso; M23=Porto Seguro; M24=Ribeira do Pombal; M25=Salvador; M26=Santa Maria da Vitória; M27=Santo Antônio de Jesus; M28=Seabra; M29=Senhor do Bonfim; M30=Serrinha; M31=Valença; M32=Vitória da Conquista. Fonte: Elaborada pelos autores. 
Na microrregião de Alagoinhas a PTF cresceu 537\% entre 1975 e 2006, essa evolução toma força a partir de 1995, quando ocorre um aumento significativo da produtividade, sendo uma das poucas microrregiões da Bahia a apresentar melhor desempenho em todos os índices parciais. Em relação à microrregião de Juazeiro, os ganhos totais de produtividade foram impulsionados pelo aumento nas produtividades parciais do trabalho, da terra e das máquinas. Nessas duas microrregiões o índice de produção cresceu acima do índice de insumos, gerando assim expressivos ganhos de produtividade.

Em Alagoinhas as principais culturas produzidas são laranja, mandioca, milho e feijão, sendo a laranja a principal cultura em termos de produção. Em 1995 a laranja apresentou crescimento de $400 \%$ na quantidade produzida em relação a 1985, enquanto outras culturas como arroz, cana de açúcar, fumo, tomate e banana, tiveram queda na produção. A produção de laranja passou de 34 mil toneladas para pouco mais de $391 \mathrm{mil}$ toneladas, um crescimento superior a 10 vezes e a mandioca também teve um crescimento expressivo, 317\%, entre 1985-1995. Porém, quando se analisa 1975 e 2006, a produção de mandioca reduziu, passando de $73 \%$ para $26 \%$, enquanto a de laranja aumentou de $13 \%$ para $71 \%$, nesse mesmo período.

O aumento da oferta de laranja acabou gerando uma redução nos preços de quase $70 \%$ entre 1985 e 1995 e 81\% de 1975 a 2006. Apesar da redução nos preços, a quantidade produzida foi tão expressiva, posicionando a microrregião como a principal produtora de laranja na Bahia em 2006.

As microrregiões com menores índices de PTF foram Brumado e Salvador, em ambas a PTF diminuiu 65\% entre 1975 e 2006, resultado da redução no índice de produção a partir de 1985. Na microrregião Salvador houve queda de $80 \%$ na quantidade total produzida de maneira geral, em especial de algumas culturas como mandioca, cana de açúcar e banana em que essa redução foi de $84 \%, 88 \%$ e $24 \%$ respectivamente durante o período analisado. Salienta-se que na microrregião de Salvador o setor agrícola é menos relevante que o setor industrial, pois estão ali concentradas as maiores indústrias do estado, em especial petroquímica, automobilística etc., além da maior oferta de serviços diversos. 
É importante destacar que a microrregião Barreiras apesar da grande relevância na produção agrícola total do estado e dos ganhos de produtividade no período analisado, seu desempenho foi inferior à média do estado da Bahia; apenas em 1995 a microrregião se iguala à média estadual e em 2006 seu desempenho é novamente inferior à média da Bahia. Em 2006 a microrregião foi responsável pelo uso de $90 \%$ de defensivos e $60 \%$ de fertilizantes, além de representar $28 \%$ do total de área colhida no estado da Bahia. Esses números revelam que o intenso uso de insumos vem gerando grande volume de produção, e daí a expectativa é de se obter maiores ganhos de produtividade nessa região.

Ademais, dificilmente determinados cultivos se disseminarão para outras localidades da Bahia, pois, conforme ressalta Viana (2004), a matriz produtiva agrícola do estado se encontra consolidada. A fruticultura concentra-se nas microrregiões Juazeiro, Bom Jesus da Lapa e Livramento do Brumado; além do Extremo Sul, onde também se concentram a pecuária e a silvicultura baiana, a cafeicultura e pecuária em Vitória da Conquista; e o oeste com grande produção de grãos, fruticultura, pecuária e criação de aves.

Apesar dessa especialização agrícola, a produção estadual é espacialmente distinta, mesmo para uma mesma cultura. Enquanto alguns municípios adotam modernas técnicas de produção e obtêm altos índices de produtividade, em outros a modernização tecnológica ainda nem chegou. Segundo Couto Filho (1999), isso ocorre porque na agricultura baiana há regiões modernas, representadas pelos polos produtivos do Extremo Sul, da região de Juazeiro e da região Oeste da Bahia, as quais convivem com regiões menos modernas, a interiorana, representada pelo semiárido baiano; e a litorânea tradicional, marcada pela lavoura cacaueira, e cultivos como café e frutas no Sul e Baixo Sul do estado. Apesar deste estudo ser quase duas décadas após o trabalho de Couto Filho (1999), permanece quase a mesma configuração agrícola, exceção para as microrregiões da faixa litorânea do norte do estado com Entre Rios, Alagoinhas e Ribeira do Pombal, que na perspectiva aqui analisada seriam caracterizadas como modernas.

Estudo da Embrapa com dados do Censo agropecuário de 2006, apontam a tecnologia como o principal fator explicativo do crescimento da produtividade, representando 68\%, enquanto trabalho e terra, respondiam por $22 \%$ e $10 \%$, respectivamente do crescimento da produção (NEVES, 2013). Os resultados obtidos neste 
estudo são relativamente semelhantes ao da EMBRAPA, pois nota-se a grande importância do capital e da mão de obra no crescimento da PTF das microrregiões do estado da Bahia. Conforme Tabela 1, tem-se que a elevação de 10\% na escolaridade da população rural e nos investimentos agropecuários aumentaria a produtividade total dos fatores em $7 \%$ e 3\%, respectivamente. Isso demonstra a relevância de investimentos em educação e insumos modernos para o setor agrícola.

Tabela 2: Resultados das estimações da PTF das microrregiões da Bahia

\begin{tabular}{lcc}
\hline \multirow{2}{*}{ Variável } & \multicolumn{2}{c}{ Modelo de regressão } \\
\cline { 2 - 3 } & \multicolumn{1}{c}{ Simples } & Efeitos fixos \\
\hline Intercepto & $87,99405^{* * *}$ & $-0,021924$ \\
Escolaridade & 0,7949386 & $0,700549^{* * *}$ \\
Investimentos & $0,0002265^{* *}$ & $0,305976^{* * *}$ \\
Assistência técnica & $-0,222564$ & $-0,173745^{*}$ \\
Intensidade de uso de fertilizantes & $-0,5287177^{*}$ & \\
Intensidade de uso de irrigação & $-0,136026$ & \\
Intensidade de uso de mecanização & $-0,260864$ & 0,190008 \\
\hline $\mathrm{R}^{2}$ & 0,155800 & \\
\hline
\end{tabular}

Nota: Nível significância $* 10 \%$; * $* 5 \% * * * 1 \%$.

Fonte: Elaborada pelos autores.

Ressalta-se também que a variável escolaridade, utilizada como proxy do fator capital humano, é primordial nos ganhos de produtividade. Melhoria no capital humano facilita a adoção de novas tecnologias, eficiência no uso de insumos nas propriedades rurais e atração de novos investimentos. Essas são mudanças estruturais importantes e que necessitam de tempo para afetar positivamente a produtividade. Porém, no modelo aplicado não se considerou a defasagem temporal, o que poderia gerar melhores resultados comparados aos apresentados aqui.

Ao estimar o modelo com as variáveis intensidade de uso de mecanização, irrigação e fertilização de forma desagregada, os resultados não foram significativos. E os dados utilizados neste trabalho não permitiram realizar tal estimação. A intensidade de mecanização e irrigação são variáveis que poderiam representar melhor a importância do 
uso da tecnologia no crescimento da produtividade. No entanto, para isso seriam necessários dados em nível municipal, como ressaltam os trabalhos de Figueiredo (2008), Gasques et al. (2004), Yee e Huffman (2002). Nesses trabalhos foi adotado o número de patentes, quantidade de publicações, investimentos em P\&D para analisar os avanços tecnológicos, porém esses dados são difíceis em escala municipal. Por esse motivo utilizou-se, neste trabalho, o investimento agregado como inserção tecnológica, pois pode-se ter número elevado de equipamentos agrícolas, mas de baixo nível de tecnológico, ou ainda o fato desses equipamentos não serem utilizados de forma eficiente, pode gerar pouco ou nenhum ganho de produtividade.

Da mesma maneira que a tecnologia tem sido apontada como um dos principais fatores explicativos da agricultura moderna, a ausência de avanços tecnológicos pode explicar, em parte, a pobreza rural. Conforme aponta Neves (2013), no Brasil, grande parte dos produtores rurais praticam uma agricultura tradicional intensiva em mão de obra, com baixos níveis de produtividade, fazendo com que $70 \%$ dos produtores rurais vivam nos limites da pobreza, enquanto $11 \%$, dos produtores que detêm uma agricultura moderna, responde por $87 \%$ do valor bruto da produção agrícola. A falta de transbordamento das novas tecnologias entre regiões pode gerar "ilhas de desenvolvimento", porém de pouco impacto positivo em análise mais global do estado. No caso da Bahia é possível notar que os maiores índices de PTF estão localizados em regiões fronteiriças, enquanto as microrregiões centrais são as menos produtivas. Isso pode indicar falta de transbordamento e conexões entre as regiões baianas mais modernas com as tradicionais e interioranas.

\section{CONSIDERAÇÕES FINAIS}

As diferentes realidades do setor agrícola na Bahia geram distintos níveis de produtividade, porém nota-se que a tecnologia e o capital humano são elementos chaves na elevação da produtividade total dos fatores.

Pode-se observar que ao longo do período analisado 1975-2006, houve uma reestruturação do setor agrícola baiano, em que produtos tradicionais como cacau, feijão, mandioca entre outros passaram a ocupar papel cada vez menos relevante na agricultura 
estadual, devido a estagnação ou diminuição da produtividade. Por outro lado, as regiões oeste e norte da Bahia foram se fortalecendo com um modelo de produção agrícola empresarial e moderno, baseado em ganhos de produtividade. As estimações realizadas permitiram identificar que os investimentos em insumos modernos e maior escolaridade afetaram positivamente a PTF.

Observa-se, de acordo com os resultados, o fortalecimento das microrregiões Barreiras, Juazeiro, Paulo Afonso e Alagoinhas no cenário agrícola baiano. Porém as microrregiões localizadas na área central do estado vêm perdendo relevância, evidenciando distintos processos de absorção da modernização agrícola, o que acaba levando a um processo excludente de parte do meio rural.

Como resultado vislumbra-se concentração da produção de determinadas culturas, em geral de maior valor, em regiões onde há maior ganho de produtividade, e que atraem mais capital para dar suporte a esse crescimento. Porém, tal fato, gera mais e mais diferenças internas no processo de evolução do meio rural.

Destarte, os resultados aqui expostos, podem servir para os decisores de política pública traçar estratégias específicas que minimizem as graves diferenças de produtividade dos fatores produtivos do meio rural baiano. Nesse sentido, entender tal fato a respeito da agricultura baiana é importante, pois dessa forma podem ser traçados medidas de políticas que gere maior benefício à população rural, e que permitam maiores índices de PTF.

\section{Nota}

\footnotetext{
${ }^{1}$ A função de produção é estuda na teoria da produção, através da produtividade obtida pelas diferentes combinações dos fatores de produção e insumos, em função da tecnologia empregada. Essa teoria é fundamental para entender a importância da tecnologia no ganho de produtividade de uma economia.
}

\section{REFERÊNCIAS}

BECKER, G. S. Human capital a theoretical and empirical analysis, with special reference to education. Third Edition, University of Chicago, NBER, New York, 1993.

BISPO, N. G. Uma análise estrutural e regional de culturas agrícolas por mesorregiões do estado da Bahia entre 2001 e 2010 com base no modelo shift and share. 2012. 186 f. Dissertação (Mestrado em Economia) - Universidade Federal da Bahia. Salvador, 2012. 
COUTO FILHO, V. A Agropecuária baiana: transformações e impactos. Bahia Análise \&Dados, Salvador SEI: v. 13, n. 4, p. 819-831, 2004a.

. Produtivismo e ocupação da mão de obra agrícola na Bahia: uma análise regionalizada da década de 1990. Bahia Análise \& Dados, Salvador SEI: v. 13, n. 4, p. 819-831, 2004b.

. (coord). Novos mundos rurais baianos. Salvador: SEI, 1999.

Domar, E. Capital expansion, rate of growth, and employment. Econometrica. 1946. p. $137-47$.

ELIAS, D. REESTRUTURAÇÃO PRODUTIVA DA AGROPECUÁRA E NOVAS DINÂMICAS TERRITORIAIS: A cidade do campo. X Encontro de Geógrafos da América Latina, São Paulo, 2005.

FERRAZ, J.; V. Quando a tecnologia muda o jogo. In: Revista Agrianual. 21 ed. São Paulo:IEG/FNP, 2016. p. 14.

FIGUEIREDO, M. G.; Retorno econômico dos investimentos em Pesquisa e Desenvolvimento (P\&D) na citricultura paulista. Escola Superior de Agricultura Luiz de Queiroz, Piracicaba, 2008.

GASQUES, J. G.; CONCEIÇÃO, J. C. P. R. Transformações estruturais agricultura e produtividade total dos fatores. IPEA. Brasília, 2000.

GASQUES, J.G. et al. Condicionantes da produtividade da agropecuária brasileira. Brasília: IPEA, 2004. 33 p.

GOMES, V.; PESSÔA, S. de A.; VELOSO, F. A. Evolução da produtividade total dos fatores na economia brasileira: uma análise comparativa. 2003.

GUILhoto, J. M.; et. al. O PIB do agronegócio no Brasil e no estado da Bahia. Londrina: SOBER, 2007.

GREENE, W. H. LIMDEP version 7.0: user's manual. Nova York: Econometric Software, 1995.

Harrod, R. F. An essay in dynamic theory. Economic Journal 1939: 14-33.

HAYAMI, Yujiro; RUTTAN, W. Vernon; Desenvolvimento agrícola: teoria e experiências internacionais. Brasília: EMPBRAPA, 1988.

IBGE, Pesquisa agrícola Municipal: Instituto Brasileiro de Geografia e Estatística.Disponível em: $<$ http://www.ibge.gov.br/home/estatistica/economia/pam/2013/default.shtm>. Acesso em: 24 Out. 2015. 
IBGE, Pesquisa Agrícola Municipal: Instituto Brasileiro de Geografia e Estatística.Disponível em:

http://www.ibge.gov.br/home/estatistica/economia/pam/2010/default.shtm>. Acesso em: 24 Jun. 2015.

IBGE. Censo Agropecuário 2006. Bahia, 2006. Disponível em: $<$ http://www.ibge.gov.br>. Acesso em: 20 Maio 2016.

JUDGE, G. G. et al. Introduction to the theory and practice of econometrics. Nova York: John Wiley \& Sons, 1988.

LUCAS, R. E. On the mechanics of economic development. Journal of Monetary Economics, v. 22, n. 1, p. 3-42, jul. 1988.

MINCER, J.. Investment in human capital and personal income distribution. Journal of Political Economy, v. LXVI, n. 4, p. 281-302, 1958.

NEVES, A.; C. Contribuição da assistência técnica e da formação profissional rural para o desenvolvimento do agronegócio. IN: TEIXEIRA, et. al.A contribuição da ciência e da tecnologia para o desenvolvimento do agronegócio. Viçosa: Suprema, 2013. cap. 10 .

PIVOTO; D. Smat faming pode trazer ganhos ao agronegócio? In: Agroanalysis. $3^{\circ}$ ed. São Paulo: FGV, 2016. vol. 36.

ROMER, P. Increasing returns and long-run growth. Journal of Political Economy, v. 94, n. 5, p. 1002-1037, 1986.

ROCHA, A. G. et. al. A agropecuária baiana: principais fatos no período 1975- 2000. In: SEI - Superintendência de estudos econômicos e sociais da Bahia. O PIB da Bahia 19752000. Salvador: SEI, 2002. 151 p. Disponível em: http://www.sei.ba.gov.br/index.php?option=com_content\&view=article\&id=1184\&Ite mid=110 Acesso em: 20 Ago. 2016.

SCHULTZ, T. W. O Capital Humano: Investimentos em Educação e Pesquisa. Rio de Janeiro: Zahar, 1973.

SCHULTZ. T. W. Valor económico de la educación. Trad. Sonia Tancredi. México: Unión Tipográfica Editorial Hispano Americana, 1968 [1963]. SCHULTZ, Theodore W. O capital humano. Investimentos em educação e pesquisa. Trad. Marco Aurélio de Moura Matos. Rio de Janeiro: Zahar Editores, 1973 [1971].

SEI - Superintendência de Estudos Econômicos e Sociais da Bahia. Boletim Técnico. 2013. Disponível em: < http://www.sei.ba.gov.br/index.php?option=com_content\&view=article\&id=2252\&Ite mid=447 > Acesso em: 18 Març. 2016. 
SOLOW, R. M. A contribution to the theory of economic growth. Quarterly Journal of Economics, [S. 1.], v. 70, p. 65-94, 1956.

THIRLWALL, A. P. A natureza do crescimento econômico: um referencial alternativo para compreender o desempenho das nações. Ipea, 2005.

VIANA, J. A. S. Agronegócio baiano: história recente de uma revolução silenciosa. Bahia Análise \& Dados, Salvador: SEI, v.13, n.4, 2004.

VIANA, G.; LIMA, J. F. Capital humano e crescimento econômico. Interações, v. 11, n. 2, p. 137-148, 2010.

VICENTE, J. R.; ANEFALOS, L.C.; CASER, D. V.Influência de Capital Humano, Insumos Modernos e Recursos Naturais na Produtividade Agrícola. In: Steven M. Helfand; Gervásio Castro de Rezende. (Org.). Região e Espaço no Desenvolvimento Agrícola Brasileiro. $1^{\circ}$ ed. Rio de Janeiro: IPEA, v. 1, p. 255-296. 2003.

VICENTE, J, R. Produtividade total de fatores e eficiência no setor de lavouras da agricultura brasileira. Revista de economia e agronegócio, v.9, nº 3, 2012.

YEE, J.; HUFFMAN, W.E.; AHEARN, M.; NEWTON, D. Sources of agricultural productivity growth at the state level, 1960-1993. In: BALL, V.E.; NORTON, G.W. (Ed.). Agriculturalproductivity: measurement and sources of growth. Norwell: Kluwer, 2002. p. 184-212.

Recebido em 04/04/2017.

Aceito para publicação em 07/02/2018. 